\title{
So werden die Konflikte entschärft
}

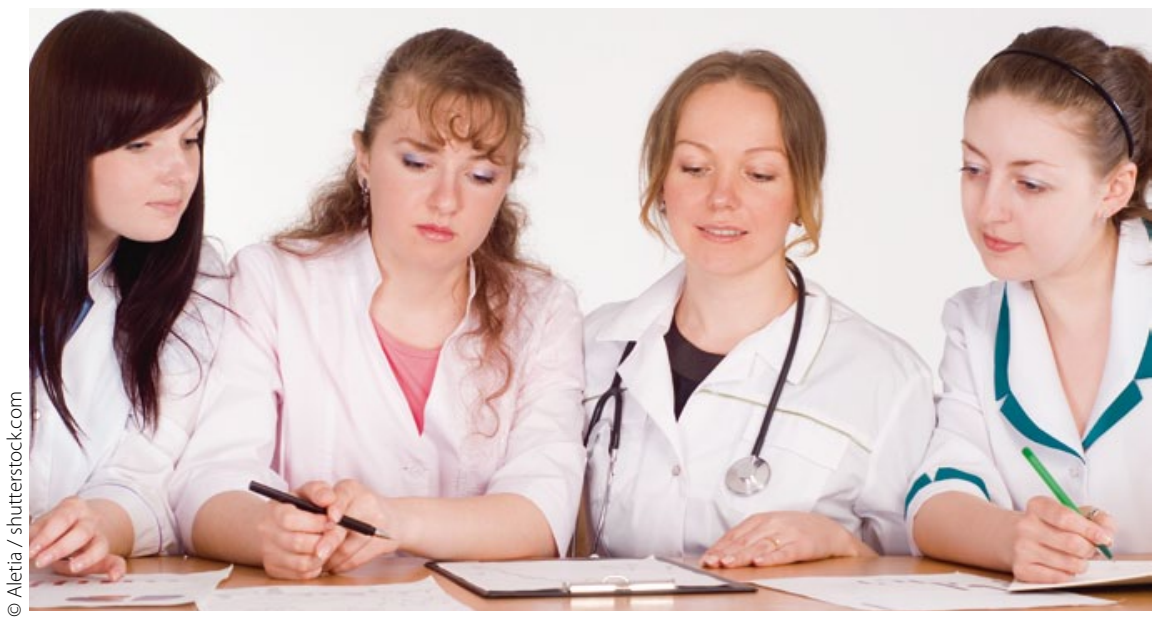

Eine klare Aufgabenverteilung vermeidet Streit.

Zoff in der Hausarztpraxis - das kommt nicht selten vor. Doch was ist zu tun, wenn es unter den Mitarbeitern kriselt? Bei einem Workshop in Heidelberg gab's Tipps.

- Streit gibt es in jedem Job - auch unter Medizinischen Fachangestellten (MFA) einer Hausarztpraxis. „Wir sind ein Weiberhaufen. Da wird sich immer mal gezofft", erzählt Julia W. bei einem Workshop in Heidelberg. Eine andere Teilnehmerin stimmt zu: „Teilweise sind die Altersunterschiede bei uns Arzthelferinnen groß, und natürlich tickt jede anders“, berichtet sie. „Konflikte im Team erfolgreich bewältigen“, ist der Titel des Workshops.

„Am Patienten wollen wir unseren Stress natürlich nicht auslassen. Da erwischt es eher die Kollegin, die beim zweiten Nachfragen noch immer nicht den Befund aus dem Labor geholt hat", gesteht eine erfahrene MFA in der Runde. Von „frauenspezifisch kleinen Reibereien“ sprechen die einen, von „Überforderung“ und „Strukturmängeln im Praxisablauf" die anderen.
Warum die Morgenrunde wichtig ist „Konflikte gibt es überall. Sie sind sogar wichtig. Sie beinhalten eine Chance, Missstände in der Hausarztpraxis zu beseitigen“, informiert Dr. Katja Götz, eine der Leiterinnen des Workshops. Wer häufige Streitereien im Team vermeiden wolle, müsse Abläufe in der Praxis optimieren. Jeder im Team müsse seine Aufgaben kennen.

Eine MFA aus der Nähe von Heidelberg hat damit gute Erfahrungen gemacht: „Jeden Morgen setzen wir uns vor der Sprechstunde kurz zusammen. Hier klären wir, wer für was zuständig ist und halten dies in einer Checkliste fest. Wer seinen Job erledigt hat, kann hier abhaken." Dieses systematische Vorgehen bringe Ruhe ins Team.

„Probleme gibt es bei uns hauptsächlich mit dem Chef", berichtet eine Angestellte, die seit über 35 Jahren in dem Job arbeitet. „Der Chef entscheidet am Donnerstag, dass er am Freitag freimachen will“, erzählt sie. Termine müssten abgesagt und Patienten vertröstet werden. Eine undankbare Aufgabe. Die Laune im Team sei entsprechend schlecht.

\section{Ist das schon Mobbing?}

Eine Auszubildende meldet sich zu Wort: „Meine Kollegin hat mich kürzlich nach Feierabend auf meinem Handy angerufen und befohlen, dass ich sofort in die Praxis zurückkommen soll, um dort den Mülleimer noch runter zu bringen“, erzählt sie aufgewühlt. Das klinge nach „Mobbing“, finden einige.

Seminarleiterin Dr. Antje Miksch nickt. Es gehe bei Konflikten nicht immer um sachlich nachvollziehbare Gründe (Sachebene), sondern viel öfter um Emotionen (Beziehungsebene). „Manchmal kann jemand einen anderen einfach nicht riechen, oder es will eine Kollegin ihre Macht als erste Kraft gegenüber den Kolleginnen ausspielen.“

Miksch rät zu Gesprächen im Team: Wichtig sei dabei, bestimmte Regeln zu beachten. „Versuchen Sie ruhig zu bleiben. Machen sie sich vor dem Gespräch Notizen, was Ihnen wichtig ist, was Sie sagen wollen und beachten Sie die IchFormel.“

Dazu gehörten Sätze wie: „Ich wünsche mir, dass Du mir zuhörst ...“ oder: „Ich möchte gerne wissen, was Dich so wütend macht." Wenig ratsam sei es dagegen, Vorwürfe in der Du-Form zu starten. Botschaften, wie: „Dir kann man nichts anvertrauen ...“ oder: „Du weißt ja immer alles besser“, könnten nicht weiterhelfen, gemeinsam Lösungen zu finden.

Grundsätzlich sei es für ein friedliches Miteinander wichtig, sich in andere hinein zu versetzen, rät Götz. „Die Halbtageskraft drückt sich beispielsweise nicht um das tägliche Putzen, wenn sie mittags geht, sondern sie muss ihr Kind vom Kindergarten abholen und ist dadurch nicht mehr in der Praxis, wenn abends sauber gemacht werden muss", nennt sie ein Beispiel.

MARION LISSON = 